3

4

5

6

7

8

9

10

11

12

13

14

15

16

17

18

19

20

21

22

23

24

25

26

27

28

29

30

\title{
VALIDATION OF THE EMPATHY INDEX IN A
} BRAZILIAN SAMPLE

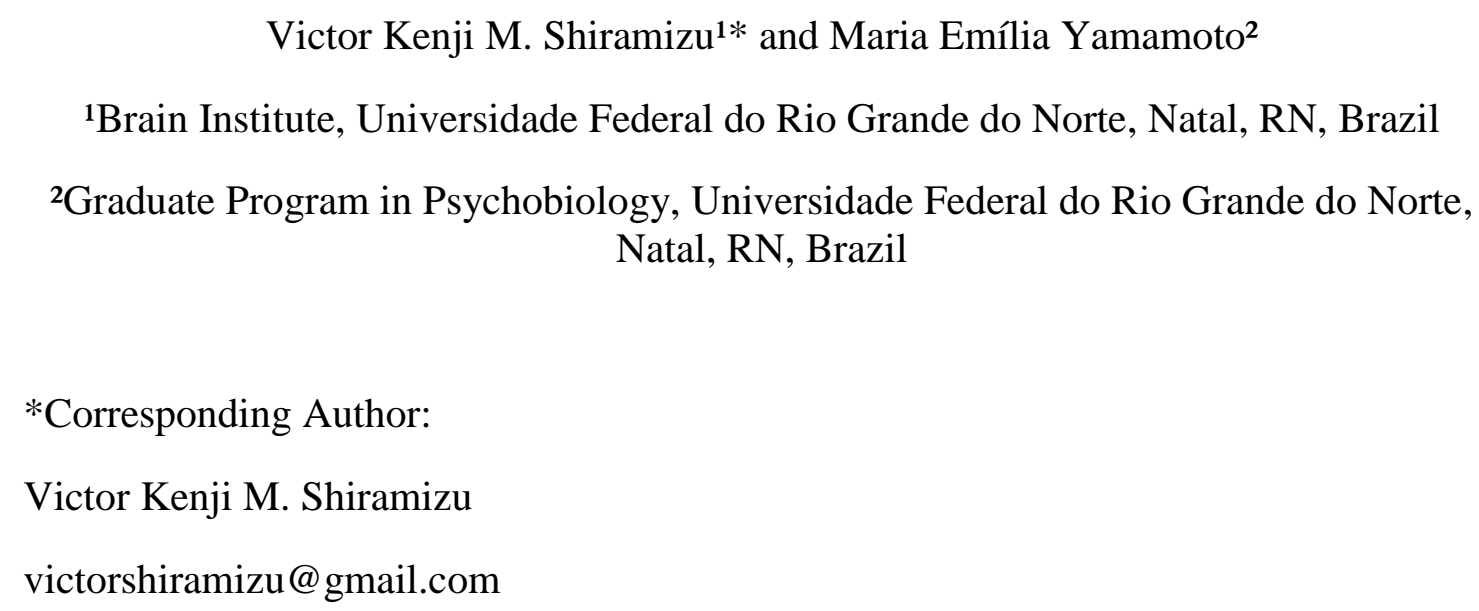

Words: 2972

14

15




\section{$1 \quad$ Abstract}

2 Definitions of the term "empathy" have long been discussed. Recent evidence suggests 3 that "empathy" and "concern" (also known as "compassion") are psychologically and 4 physiologically distinct. These distinctions directly affect the psychometric measures 5 used to assess empathy. A new measure called the Empathy Index (EI) has been 6 proposed that assesses empathy strictly in terms of emotional contagion. However, this 7 measure has not been validated using Brazilian Portuguese language. Our objective was 8 therefore to translate, culturally adapt, and examine the psychometric properties of the 9 EI in a Brazilian population. We also examined the EI's relationship with the 10 Interpersonal Reactivity Index (IRI). In Study 1 (N=483), we explored the relationship between EI and IRI through factor analysis. Empathy and concern loaded on different factors. The EI subscales showed adequate Cronbrach's alphas and concern, but not empathy, predicted contributions during an economic game. In Study $2(\mathrm{~N}=215)$, confirmatory factor analyses confirmed the factorial structure of EI and its relation with IRI. Therefore, we consider that the Brazilian version of the EI showed good evidence of both validity and reliability.

Keywords: empathy; concern; scale validation; empathy index; cross-cultural psychology. 


\section{Introduction}

Empathy is a phenomenon broadly investigated in the psychological sciences that has received substantial attention over the last decade (Davis, 2015). One of the reasons for this strong focus on empathy is that individual differences in empathy are a good predictor of prosocial behavior (Davis, 2015). However, empathy has been defined in many different ways, leading to its use in eight distinct but related phenomena, for example: cognitive empathy, facial empathy, and compassion (Batson, 2009; Cuff, Brown, Taylor, \& Howat, 2014).

According to Zaki (2017), "empathy" is an umbrella term, representing multiple processes that help organize the study of interpersonal emotions. Some authors define empathy to include both cognitive and affective components (e.g., Oliveira-Silva \& Gonçalves, 2011), while other definitions include just one component (for a review, see Cuff, Brown, Taylor, \& Howat, 2014). For example, Batson, Fultz, and Schoenrade (1987) define empathy in a narrow emotional sense to refer to a type of emotional congruence. By contrast, based on evidence from developmental and affective neuroscience, Decety and Cowell (2014) argue that empathy can be divided into three components: emotional sharing, empathic concern, and perspective taking. In this account of empathy, emotional sharing is related to motivation in caring and helping another individual in distress, empathic concern is a motivational component that promotes positive feelings toward others regarding welfare, and perspective taking is a cognitive component that enables an individual to infer what another individual is thinking or feeling.

Bloom $(2014,2017)$ defines empathy as the ability to experience what an individual believes others are experiencing. More importantly, based on both psychometric and neurophysiological studies, Bloom proposed that empathy is distinct from empathic concern.

Several unidimensional to multidimensional measures have been developed to assess empathy (for a review, see Neumann, Chan, Boyle, Wang, \& Westbury, 2015). Regarding multidimensional measures, the Interpersonal Reactivity Index (IRI) is one of the most widely used measures for assessing different aspects of social functioning (Siu \& Shek, 2005). Developed by Davis (1980), the IRI is a self-report measure composed of four subscales: fantasy (the ability to identify with characters from a movie and/or book), personal distress (feeling distressed or anxious when imagining other's suffering), empathic concern (hereon referred to as concern and defined as showing concern about other's welfare), and perspective taking (the ability to infer mental states or thoughts of others). The IRI has been translated and validated for the Brazilian population showing satisfactory psychometric indicators of structural consistency (Sampaio, Guimarães, Camino, Formiga, \& Menezes, 2011). Although the IRI is a measure widely used on studies exploring empathy, it does not assess the construct proposed by Bloom $(2014,2017)$. 
1 Jordan, Amir, and Bloom (2016) proposed a new measure, called the Empathy Index

2 (EI), to evaluate individual differences in the propensity to feel what others feel. The EI

3 comprises two subscales; empathy and behavioral contagion. The first subscale

4 (empathy) assesses empathy in the strict sense of emotional contagion (i.e., the degree

5 to which individuals feel what people around them are feeling). The second subscale

6 (behavioral contagion) assesses the tendency to imitate what people around them are

7 doing. Jordan et al. argue that empathy triggers affect and behavioral contagion triggers

8 behavior. Based on these two new subscales, they explored the relationship between EI

9 and IRI subscales through a series of factor analyses, verifying that the subscales

10 empathy, behavioral contagion, and personal distress loaded on a factor they labeled

"contagion". By contrast, concern and perspective taking loaded on a factor they labeled "other-regarding". Interestingly, they also found concern but not empathy was a predictor of prosocial actions, as measured through responses in a public goods game (PGG). Collectively, these findings suggest that empathy and concern are psychologically distinct.

The EI has not yet been translated and validated into another language. Thus, it is unclear whether the factor structure reported by Jordan et al. generalizes to other cultures. Additionally, no scale assessing empathy as defined by Jordan et al. (2016) is available in Brazilian Portuguese. Therefore, our main objective was to translate, culturally adapt, and examine the internal consistency and factor structure of a Brazilian version of the Empathy Index.

In Study 1, we translated and adapted the two subscales of the EI to a Brazilian population and tested their relationship with the subscales of the IRI using factor analysis. In Study 2, we used confirmatory factor analyses to provide additional evidence of the psychometric properties of the EI.

\section{Study 1}

Methods

\section{Participants}

Four hundred and eighty three participants (332 women, $151 \mathrm{men} ; M_{\text {age }}=28.41$ years, $S D=8.65$ years) took part on this online study. Participants were recruited through social media and email and completed the measures described below. The protocol was approved by the local ethical committee of the Federal University of Rio Grande do Norte (protocol number: 80926817.0.0000.5537). All subjects gave written informed consent in accordance with the Declaration of Helsinki. 
The IRI (Davis, 1983; Brazilian version: Sampaio et al., 2011) consists of 28 -items that assess individual differences in cognitive and affective empathy based on four subscales: fantasy (Cronbach's $\alpha=0.82)$, personal distress $(\alpha=0.76)$, perspective taking $(\alpha=0.68)$, and empathic concern $(\alpha=0.75)$. Items vary from 1 (Does not describe me well) to 5 (Describes me very well). Item order was fully randomized.

\section{Empathy Index (EI)}

The EI (Jordan, Amir, \& Bloom, 2016) has 14 Likert-type scale items measuring individual differences in emotional and behavioral contagion. Seven items compose the behavioral contagion subscale (e.g., If I see a video of a baby smiling, I find myself smiling) and the other 7 items compose the empathy subscale (e.g., If I see someone who is excited, I will feel excited myself). Participants respond using a 1 (Does not describe me well) to 5 (Describes me very well) scale. Cronbach's $\alpha$ for empathy and behavioral contagion subscales were $>0.70$. Item order was fully randomized.

\section{One-shot Public Goods Game (PGG)}

Participants played a one-shot PGG based on Rand (2012). We first informed participants that they were to be placed in groups of four. We then asked them to imagine that they had 40 reais (Brazilian currency) and could contribute any amount to a common project. They were also informed that the amount they contributed to the common project would be doubled and divided equally among the group members. After these instructions, we asked the participants to answer comprehension questions to assess that they had understood the game's payoff structure. These questions were "What level of contribution earns the most money for the group as a whole?" and "What level of contribution earns the most money for you personally?".

\section{Demographic questionnaire}

A short demographic questionnaire assessed sex, age, and educational level.

\section{Cross-cultural Adaptation}

The cross-cultural adaptation process of the EI was based on the guidelines proposed by Borsa, Damásio, and Bandeira (2012). Two translators (Brazilian Portuguese speakers with an advanced level of English) independently translated the EI into Brazilian Portuguese. The translated versions were then evaluated by an independent researcher with experience in translation, adaptation, and validation of psychometric scales to verify any semantic divergence. Next, these two translated versions were merged. The merged version was then translated back into English again by a third translator (native English speaker fluent in Brazilian Portuguese) and compared to the original version in English to verify accuracy. Table 1 shows the final version of Empathy Index for a Brazilian population. 


\section{Data Analysis}

3 Case mean imputation was conducted for items that had missing data. This technique is

4 recommended when missing data correspond to less than $20 \%$ (Roth, Switzer, \&

5 Switzer, 1999). We conducted a factor analysis (FA) to determine the numbers of

6 factors. FA used the principal factor method and promax rotation, since the original

7 study by Jordan et al. (2016) has used this approach and also because it allows

8 correlations between the factors (Pasquali, 2005). Sampling adequacy was assessed via

9 Kayser-Meyer-Olkin (KMO, values above 0.50 are suitable for factor analysis) and

10 Barlett's sphericity (it should be significant, $p<0.05$, Williams, Onsman, \& Brown,

11 2010). Reliability of each factor was assessed through Cronbach's $\alpha$. Reliability values

$12 \geq 0.70$ are typically considered adequate (Cronbach, 1951).

In order to verify convergent validity, we conducted multiple regression analyses to assess the association between contributions during the one-shot public goods game and both the concern and empathy subscales. Only participants who had understood the comprehension question were included in these analyses.

\section{Results}

\section{Factor Analysis}

Because KMO indicated sampling adequacy for individual items $(K M O=0.87)$ and the sublevel scale $(K M O=0.71)$, we conducted a factor analysis with promax rotation based on standardized composite measures of each scale.

Two factors were extracted that explained $59.95 \%$ of the variance. Factor 1 contained the subscales fantasy, personal distress, behavioral contagion, and empathy and explained $41.55 \%$ of the variance. Factor 2 contained the subscales perspective taking and concern and explained $18.40 \%$ of the variance. These findings are in accordance with Jordan et al's (2016) results because both sets of results show that the empathy subscale loaded on a factor distinct from concern. However, in Jordan et al's study of EI, the fantasy subscale loaded on both factors. Therefore, we named our Factor 1 Contagion factor and our Factor 2 Other-regarding. Table 2 shows all factor loadings for the subscale composites. Internal consistencies were evaluated using Cronbach's $\alpha$ and were 0.75 and 0.72 for empathy and behavioral contagion, respectively.

For the PGG analyses, nine participants were excluded because they did not respond correctly to the comprehension questions, suggesting they did not fully understand the payoff structure. Separate linear regressions showed that concern significantly predicted contributions during one-shot PGG ( $\mathrm{b}=0.118$, CI: [1.142, 8.595], $p=0.011, \mathrm{R}^{2}=$

$0.012)$. However, empathy did not significantly predict PGG contributions ( $b=0.028$,

41 CI: $\left.[-2.247,4,267], p=0.542, \mathrm{R}^{2}=0.001\right)$. When concern and empathy were included 
1 in the same model, concern $(b=0.128, \mathrm{CI}$ : [1.190, 9.374], $p=0.011)$, but not empathy

2 (b = -0.025, CI: [-4.428, 2.679], $p=0.623)$, predicted one-shot PGG contributions.

3

4

5

6

7

8

\section{Study 2}

\section{Participants}

Two hundred fifteen participants ( 153 women, 62 men; $M_{\text {age }}=26.54$ years, $S D=8.24$ years) had completed the surveys described below. The recruitment and procedures were as described on Study 1. None of the participants in Study 2 had taken part in Study 1.

\section{Data Analysis}

In order to verify whether the hypothesized structure of relationships between the Brazilian version of Empathy Index and the IRI fitted the data well, we conducted a confirmatory factor analyses (CFA) using the widely used maximum likelihood method of estimation (Brown, 2015). The indices used to assess the model fits were: chisquared value $\left(\chi^{2}\right)$ and corresponding $p$-value (when $100<\mathrm{N}<300$, it is recommended not to be significant), $\chi^{2} / \mathrm{df}$ index (values less than 2 indicate good fit), Goodness of Fit Index - GFI (recommended values > 0.90), Comparative Fit Index - CFI (recommended values $>0.90$, Normed Fit Index - NFI (recommended values $>0.90$ ), and Root Mean Square Error of Approximation - RMSEA (recommended values < 0.08) (McDonald \& Ho, 2002).

\section{Results}

\section{Factor Structure}

Initially, we conducted factor and internal consistency analyses using the same methods described as in Study I. We found adequate values for the $K M O(0.76)$ when considering the standardized composite scores. Two factors emerged and explained $59.91 \%$ of the variance. As in Study 1, concern and empathy loaded on different factors (Table 3). The Cronbach's $\alpha$ for the empathy subscale was $\alpha=0.77$ and for the behavioral contagion was $\alpha=0.76$. These findings replicated those of the study I.

Two models were tested to assess the structure between EI and IRI through CFA. In the first model (one-factor), we allowed the 6 subscale composites to load on a single and one dimensional factor. In the second model (two-factor), we allowed the fantasy, personal distress, empathy, and behavioral contagion subscales to load on the contagion factor. The perspective taking and concern subscales were allowed to load on the otherregarding. Therefore, this model was set up with two correlated factors. The results indicated that the two-factor model fit the data better, $\chi^{2}(8)=8.87$ (Figure 1), than the one-factor model, $\chi^{2}(9)=26.36, \Delta \chi^{2}(1)=17.49, p<0.001$. Table 4 shows the fit indices of models analyzed through CFA. 
2 In order to verify discriminant validity, we tested sex differences for contagion and 3 other-regarding factors. Women scored higher than men in contagion, $t(213)=3.36$,

$4 p<0.001, d=0.51$. Women also scored higher than men in other-regarding factor, $t(213)$

$5=4.00, p<0.001, d=0.60$ (Figure 2 ).

7 Discussion

8 The objective of this study was to translate, adapt, and validate the Empathy Index to

9 Brazilian Portuguese. We found adequate Cronbach's alpha, convergent and discriminant validity, as well as suitable model fit.

In two studies, we confirmed that the subscale empathy from the Brazilian version of the EI and the subscale concern from IRI loaded on different factors. The empathy subscale loaded on the Contagion factor along with the behavioral contagion, fantasy, and personal distress subscales. On the other hand, the concern subscale loaded on the Other-regarding factor, along with the perspective taking subscale. These results are consistent both with Jordan et al's (2016) findings and Bloom's (2017) proposal that empathy is the ability to share the other's feeling. Our results also show that the Contagion factor captures emotional/affective empathy, while the Other-regarding factor captures abilities like caring and understanding the other's feeling (cognitive empathy). We found that the fantasy subscale loaded on the Contagion factor, different from the original EI study. In the validation study of IRI to Brazilian Portuguese, Sampaio and colleagues (2011) found participants scored higher on fantasy subscale when compared to other subscales. They argued one possibility is that Brazilians tend to strongly identify themselves with fictional characters and this identification would have the potential to promote affective empathy. Thus, at least for the Brazilian population, it makes sense the fantasy subscale has loaded on the Contagion factor

We also observed evidence of convergent validity for the Brazilian EI in Study 1. Concern, but not empathy, was related to prosocial behavior assessed via the one-shot public goods game. Concern positively predicted contributions. These findings were in accordance with results from other studies investigating the role of concern in prosocial behavior. For example, Leiberg, Klimecki, and Singer (2011) found that compassion (empathic concern) training increased prosocial behavior toward strangers during a virtual game designed to evaluate reciprocity and costly helping behavior. Moreover, Klimecki, Leiberg, Ricard, and Singer (2013) found that participants exposed to videos describing suffering (due to injuries or natural disasters) increased negative affect as well as activation of brain areas (anterior insula and anterior midcingulate cortex) related to empathy for pain. Importantly, our results regarding to PGG replicated the Jordan et al's (2016) findings, providing further evidence for the validity of the Brazilian version of the EI. 
This was the first validation study of the Empathy Index to assess model fit. Through the confirmatory factor analyses, we tested two models. Although the one-factor model achieved suitable fit, the bi-factor model showed better data fit $\left[\chi^{2}(8)=8.826, \mathrm{GFI}=\right.$ $0.987, \mathrm{CFI}=0.997, \mathrm{NFI}=0.966, \mathrm{RMSEA}=0.022]$. This model consisted of: otherregarding factor, which included the perspective taking and concern subscales from IRI; and the contagion factor, which contained the fantasy and personal distress subscales from IRI as well as the empathy and behavioral contagion from EI. Therefore, these findings reinforce that empathy is psychologically distinct from concern.

In order to verify discriminant validity, we investigated sex differences in otherregarding and behavioral contagion factors. We found women scored higher on both factors when compared to men. These results are in accordance with past studies on sex differences in empathic processes (Baron-Cohen, 2010; Baron-Cohen \& Wheelwright, 2004). Thus, the Empathy Index might be used as a measure to investigate sex differences in empathic processes.

Some limitations need to be highlighted. First, we had a higher women's proportion on both studies. Second, participants from study II had a homogenous educational level, since the majority of them were grad and undergraduate students recruited through email lists.

In summary, the Empathy Index (EI) proposed by Jordan et al. (2016) was translated and adapted to Brazilian Portuguese. Findings from two independent studies showed reliable psychometrics properties for the Brazilian version, as well as suitable model fit based on theoretical predictions. Therefore, the Brazilian version of the EI is a valid measure for future studies evaluating concern and empathy as independent psychological constructs in Brazilian samples.

\section{Acknowledgment}

We thank Matthew R. Jordan for the advice before and after the data collection. We also thank Benedict C. Jones for his comments on the manuscript.

\section{Competing interests statement}

The authors declare no competing interests.

\section{Author's contribution statement}

VKM-S contributed to conception of research; VKM-S collected the data; VKM-S and M-Y contributed to interpretation of data; VKM-S and ME-Y wrote the manuscript. All authors read and approved the final manuscript. 


\section{References}

Baron-Cohen, S. (2010). Empathizing, systemizing, and the extreme male brain theory of autism. In: Sex Differences in the Human Brain, their Underpinnings and Implications (pp. 167-175). Elsevier. doi:10.1016/b978-0-444-53630-3.00011-7

Baron-Cohen, S., \& Wheelwright, S. (2004). The Empathy Quotient: An Investigation of Adults with Asperger Syndrome or High Functioning Autism, and Normal Sex Differences. Journal of Autism and Developmental Disorders, 34, 163-175. doi:10.1023/b:jadd.0000022607.19833.00

Batson, C. D. (2009). These Things Called Empathy: Eight Related but Distinct Phenomena. In: The Social Neuroscience of Empathy (pp. 3-16). The MIT Press. doi:10.7551/mitpress/9780262012973.003.0002

Batson, C. D., Fultz, J., \& Schoenrade, P. A. (1987). Distress and empathy: Two qualitatively distinct vicarious emotions with different motivational consequences. Journal of personality, 55(1), 19-39.

Bloom, P. (2014, September 10). Against empathy. Boston Review. Retrieved from http://bostonreview.net/forum/paul-bloom-against-empathy

Bloom, P. (2017). Empathy and Its Discontents. Trends in Cognitive Sciences, 21, $24-$ 31. doi:10.1016/j.tics.2016.11.004

Borsa, J. C., Damásio, B. F., \& Bandeira, D. R. (2012). Adaptação e validação de instrumentos psicológicos entre culturas: algumas considerações. Paidéia, 22(53). dx.doi.org/10.1590/S0103863X2012000300014

Brown, T. A. (2015). Confirmatory factor analysis for applied research. Guilford Publications. New York: Guilford Press.

Cronbach, L. J. (1951). Coefficient alpha and the internal structure of tests. Psychometrika, 16, 297-334. doi:10.1007/bf02310555

Cuff, B. M., Brown, S. J., Taylor, L., \& Howat, D. J. (2014). Empathy: A Review of the Concept. Emotion Review, 8, 144-153. doi:10.1177/1754073914558466

Davis, M. H. (1983). Measuring individual differences in empathy: Evidence for a multidimensional approach. Journal of Personality and Social Psychology, 44, 113-126. doi:10.1037/0022-3514.44.1.113

Decety, J., \& Cowell, J. M. (2014). The complex relation between morality and empathy. Trends in Cognitive Sciences, 18, 337-339. doi:10.1016/j.tics.2014.04.008

Jordan, M. R., Amir, D., \& Bloom, P. (2016). Are empathy and concern psychologically distinct? Emotion, 16, 1107-1116. doi:10.1037/emo0000228

Klimecki, O. M., Leiberg, S., Ricard, M., \& Singer, T. (2013). Differential pattern of functional brain plasticity after compassion and empathy training. Social Cognitive and Affective Neuroscience, 9, 873-879. doi:10.1093/scan/nst060 
Leiberg, S., Klimecki, O., \& Singer, T. (2011). Short-Term Compassion Training Increases Prosocial Behavior in a Newly Developed Prosocial Game. (A. V. García, Ed.) PLoS ONE, 6, e17798. doi:10.1371/journal.pone.0017798

McDonald, R. P., \& Ho, M.-H. R. (2002). Principles and practice in reporting structural equation analyses. Psychological Methods, 7, 64-82. doi:10.1037/1082989x.7.1.64

Neumann, D. L., Chan, R. C., Boyle, G. J., Wang, Y., \& \& Westbury, H. R. (2015). Measures of Empathy: Self-Report, Behavioral, and Neuroscientific Approaches. In: Measures of Personality and Social Psychological Constructs (pp. 257-289). Elsevier. doi:10.1016/b978-0-12-386915-9.00010-3

Oliveira-Silva, P., \& Gonçalves, Ó. F. (2011). Responding empathically: A question of heart, not a question of skin. Applied psychophysiology and biofeedback, 36(3), 2011. doi.org/10.1007/s10484-011-9161-2

Pasquali, L. (2005). Análise fatorial para pesquisadores. Porto Alegre: Artmed.

Rand, D. G. (2012). The promise of Mechanical Turk: How online labor markets can help theorists run behavioral experiments. Journal of Theoretical Biology, 299, 172-179. doi:10.1016/j.jtbi.2011.03.004

Roth, P. L., Switzer III, F. S., \& Switzer, D. M. (1999). Missing data in multiple item scales: A Monte Carlo analysis of missing data techniques. Organizational research methods, 2(3), 211-232.

Sampaio, L. R., Guimarães, P. R. B., dos Santos, C. P., Formiga, N. S., \& Menezes, I. G. (2011). Estudos sobre a dimensinalidade da empatia: traduçao e adaptaçao do Interpersonal Reactivity Index (IRI). Psico, 42(1), 67-76.

Schroeder, D. A., Graziano, W. G., \& Davis, M. H. (2015). Empathy and Prosocial Behavior. In: The Oxford Handbook of Prosocial Behavior. Oxford University Press. doi:10.1093/oxfordhb/9780195399813.013.026

Siu, A. M., \& Shek, D. T. (2005). Validation of the Interpersonal Reactivity Index in a Chinese Context. Research on Social Work Practice, 15, 118-126. doi:10.1177/1049731504270384

Williams, B., Onsman, A., \& Brown, T. (2010). Exploratory factor analysis: A five-step guide for novices. Australasian Journal of Paramedicine, 8(3).

Zaki, J. (2017). Moving beyond Stereotypes of Empathy. Trends in Cognitive Sciences, 21, 59-60. doi:10.1016/j.tics.2016.12.004. 
Table 1

Translation and cross-cultural adaptation of Empathy Index for the Brazilian Portuguese.

\begin{tabular}{ll}
\hline & \multicolumn{1}{c}{ Empathy } \\
\hline Item & \multicolumn{1}{c}{ English version } \\
1 & $\begin{array}{l}\text { If I see someone who } \\
\text { is excited, I will feel } \\
\text { excited myself. }\end{array}$ \\
& $\begin{array}{l}\text { I sometimes find } \\
\text { myself feeling the } \\
\text { emotions of the } \\
\text { people around me, } \\
\text { even if I don't try to } \\
\text { feel what they're } \\
\text { feeling. }\end{array}$
\end{tabular}

If I'm watching a movie and a character

3 injures their leg, I will feel pain in my leg.

If I hear a story in which someone is scared, I will imagine how scared I would be in that situation and begin to feel scared myself.

If I hear an awkward 5 story about someone else, I might feel a little embarrassed.

I can't watch shows in which an animal is 6 being hunted, because I feel nervous as if I am being hunted.

If I see someone 7 fidgeting, I'll start feeling anxious too.
Se eu vejo alguém animado, eu me sentirei animado.

Às vezes eu me pego sentindo as emoções de pessoas ao meu redor, mesmo se eu não tento sentir o que elas estão sentindo.

Se eu estou assistindo um filme e um personagem machuca a perna, eu sentirei dor em minha perna.

Se eu ouço uma história na qual alguém está assustado, eu imaginarei o quanto assustado(a) eu poderia estar nessa situação e começarei a me sentir assustado(a).

Se eu ouço uma história embaraçosa sobre alguém, eu posso sentir-me um pouco envergonhado(a).

Eu não consigo assistir programas nos quais um animal está sendo caçado por outro, porque eu me sinto nervoso como se eu estivesse sendo caçado.

Se alguém está inquieto, eu também começarei a me sentir ansioso.
I catch myself crossing my arms or legs just like the person I'm talking to.

If I see a video of a baby smiling, I find myself smiling.

If I see someone suddenly looking away, I'll automatically look in the direction they are looking.

If I'm watching someone walking on a balance beam, I will lean when they lean.

If I'm having a conversation with someone and they scratch their nose, I will also scratch my nose.
Eu me pego cruzando os braços ou as pernas tal como a pessoa que eu estou conversando.

Se eu vejo um vídeo de um bebê sorrindo, percebo que estou sorrindo.

Se eu vejo alguém repentinamente olhando para longe, eu automaticamente olharei na mesma direção.

Se eu estou assistindo alguém andando em uma linha de equilíbrio, eu me inclinarei quando ele(a) se inclinar.

Se eu estiver conversando com alguém e esse coçar o nariz, eu também irei coçar o meu nariz. 
Table 2

Factor loadings for subscale composite scores (extraction: principal factor method, rotation: promax) from study I.

\begin{tabular}{lccc}
\hline \multicolumn{1}{c}{ Subscale } & Contagion factor & Other-regarding factor & Uniqueness \\
\hline Fantasy & $\mathbf{. 4 2 3}$ & .089 & 0.766 \\
Concern & .148 & $\mathbf{. 5 2 8}$ & 0.600 \\
Personal distress & $\mathbf{. 5 8 9}$ & -.093 & 0.713 \\
Perspective taking & -.153 & $\mathbf{. 6 4 7}$ & 0.683 \\
Empathy & $\mathbf{. 6 2 6}$ & .182 & 0.432 \\
Behavioral contagion & $\mathbf{. 6 6 6}$ & -.124 & 0.645
\end{tabular}


Table 3

Factor loadings for subscale composite scores (extraction: principal factor method, rotation: promax) based on the sample from the study II.

\begin{tabular}{lccc}
\hline \multicolumn{1}{c}{ Subscale } & Contagion factor & Other-regarding factor & Uniqueness \\
\hline Fantasy & $\mathbf{. 3 3 1}$ & .151 & 0.792 \\
Concern & .128 & $\mathbf{. 5 8 4}$ & 0.530 \\
Personal Distress & $\mathbf{. 6 2 0}$ & -.187 & 0.754 \\
Perspective taking & -.154 & $\mathbf{. 6 5 3}$ & 0.701 \\
Empathy & $\mathbf{. 6 1 9}$ & .164 & 0.438 \\
Behavioral contagion & $\mathbf{. 5 3 8}$ & .080 & 0.639
\end{tabular}


Table 4

Fit Indices for Confirmatory Factor Analysis Models. GFI: Goodness of Fit Index; CFI: Comparative Fit Index; NFI: Normed Fit Index; RMSEA: Root Mean Square Error of Aproximation.

\begin{tabular}{cccccccc}
\hline Model & $\boldsymbol{\chi}^{\mathbf{2}}$ & $\boldsymbol{d} \boldsymbol{f}$ & $\boldsymbol{\chi}^{\mathbf{2}} / \boldsymbol{d} \boldsymbol{f}$ & GFI & CFI & NFI & RMSEA \\
\hline One factor & 26.24 & 9 & 2.915 & 0.960 & 0.929 & 0.899 & 0.095 \\
Two factors & 8.826 & 8 & 1.103 & 0.987 & 0.997 & 0.966 & 0.022 \\
\hline
\end{tabular}




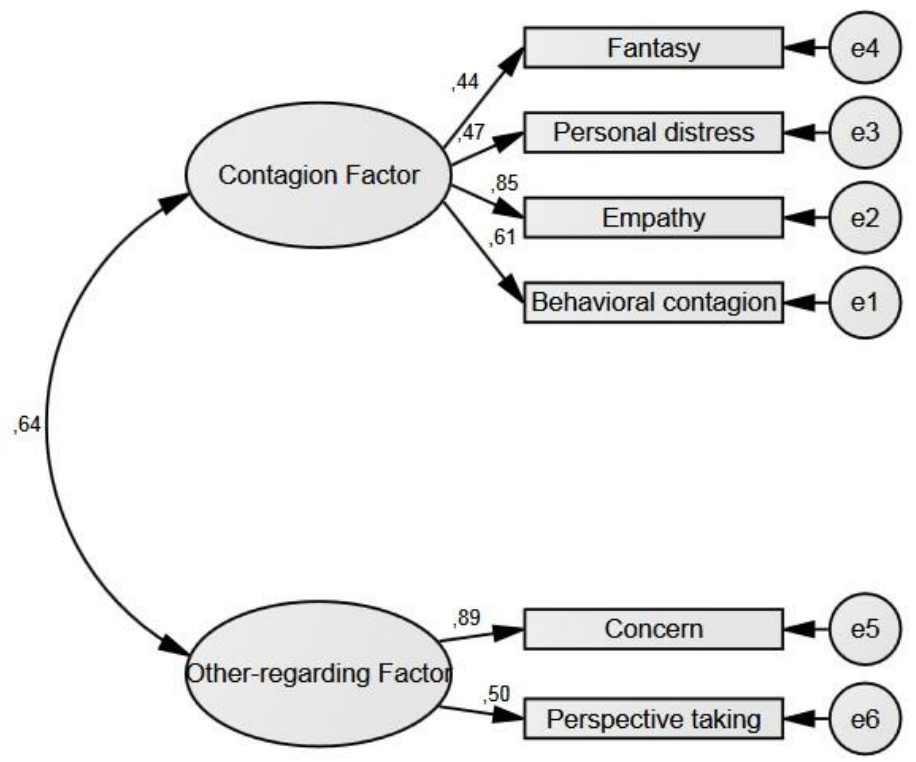

Figure 1. Two-factor model of the Empathy Index obtained from a sample of 215 participants. Standardized estimates: regression coefficients are indicated close to unidirectional arrows; squared correlation is represented close to bidirectional arrow. 


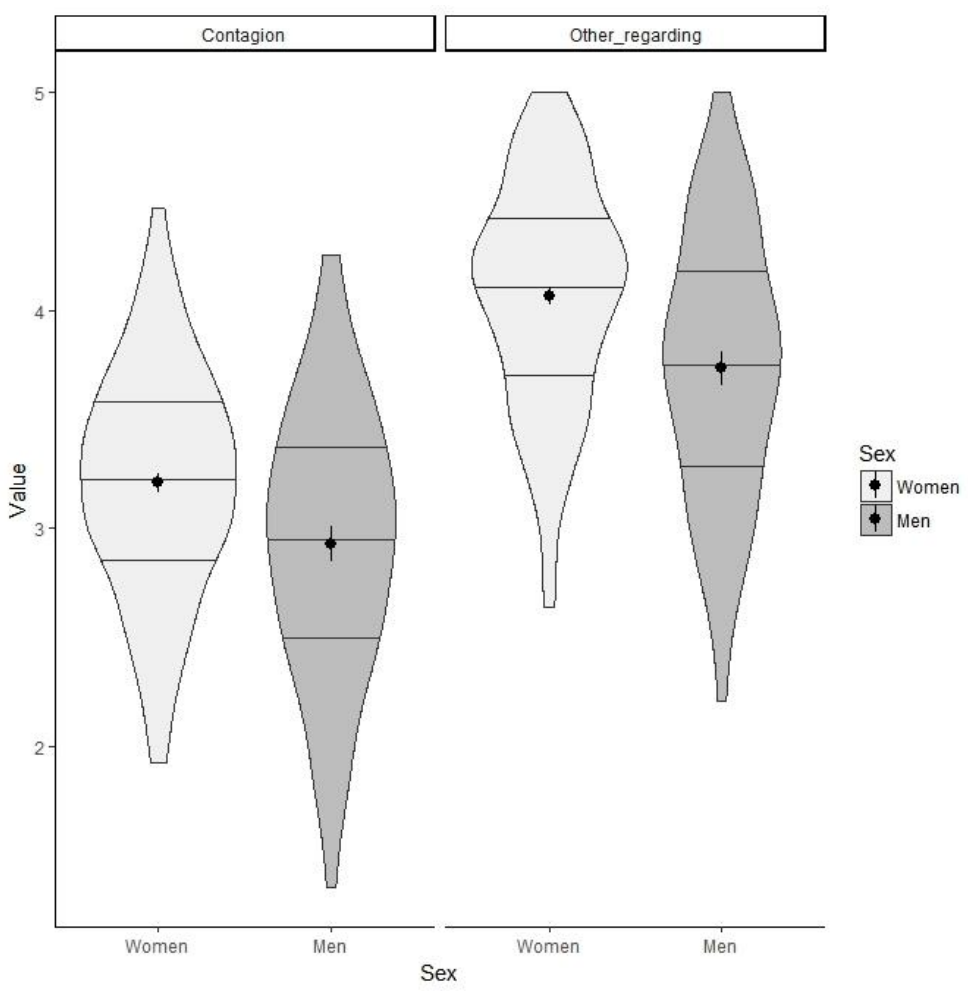

Figure 2. Sex differences on contagion and other-regarding factors represented by the density plots. Black dots represent the mean values. Quartiles are represented by horizontal lines inside the plots. 